\title{
Prediction of eating disorder symptoms among female students based on experiential avoidance and mindfulness
}

\author{
Mohsen Kachooei ${ }^{1}$, Emad Ashrafi ${ }^{1}$, Mona Momeni Rouchi ${ }^{2}$, Anahita Hosseinpour ${ }^{3}$, Parandis Hafezi ${ }^{4}$ \\ ${ }^{1}$ Assistant Professor, Department of Psychology, Faculty of Humanities, University of Science and Culture, Tehran, Iran \\ ${ }^{2}$ MA of the Personality Psychology, Islamic Azad University, Science and Research Branch, Tehran, Iran \\ ${ }^{3}$ MA Student of the Psychology of Family Therapy, Department of Psychology, Faculty of Humanities, University of \\ Science and Culture, Tehran, Iran \\ ${ }^{4}$ BS Student of Psychology, Department of Psychology, Tehran Medical Sciences Branch, Islamic Azad University, Tehran, Iran
}

\begin{abstract}
Background: Based on emotional regulation models of eating pathology, disordered eating behaviors are maladaptive efforts to avoid or escape from aversive internal experiences. The aim of the present study was to investigate the relationship between experiential avoidance and mindfulness with eating disorders symptomology among undergraduate female students.

Materials and methods: In this descriptive-correlative research, 350 eligible female students selected by convenient sampling method in 2016. Questionnaires of Eating Disorders Diagnostic Scale (EDDS), The Acceptance and Action Questionnaire-II (AAQ-II), and Mindful Attention Awareness Scale (MAAS) were used. Data analysis was done by Pearson correlational analysis and multiple regression analysis.

Results: There found a positive significant relationship between eating disorder symptoms and experiential avoidance $(\mathrm{P}<0.01)$; and a negative significant relationship between eating disorder symptoms and mindfulness $(\mathrm{P}<0.01)$. The results of multiple regression analysis indicated that both constructs of experiential avoidance and mindfulness were significant predictors of eating disorders symptomology.

Conclusion: According to the results, it can be concluded that avoidance of internal experiences and low mindfulness may play a role in disordered eating. Therefore, development of regulation strategies for applying in exposure with unpleasant experiences may be useful in prevention and treatment of eating disorder.
\end{abstract}

Keywords: Eating and Feeding Disorders, Experiential avoidance, Mindfulness.

Cited as: Kachooei M, Ashrafi E, Momeni Rouchi M, Hosseinpour A, Hafezi P. Prediction of eating disorder symptoms among female students based on experiential avoidance and mindfulness. Medical Science Journal of Islamic Azad University, Tehran Medical Branch 2019; 29(1): 92-99.

Correspondence to: Mohsen Kachooei

Tel: +982144218171

E-mail: kachooei.m@gmail.com

ORCID ID: 0000-0002-3070-4100

Received: 1 Sep 2018; Accepted: 29 Oct 2018 
مجله علوم يزشكى دانشگاه آزاد اسلامى

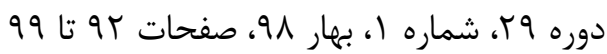

Original

Article

\section{ييش بينى نشانه هاى اختلال خوردن در دانشجويان دختر براساس اجتناب تجربى و ذهن آتاهى}

\section{محسن كجويى'، عماد اشرفى'، منا مومنى روجى '، آناهيتا حسين يور ‘ّ، يرنديس حافظى}

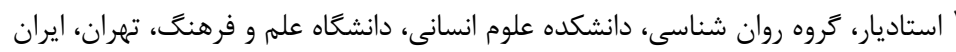

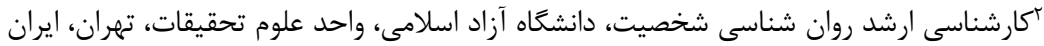

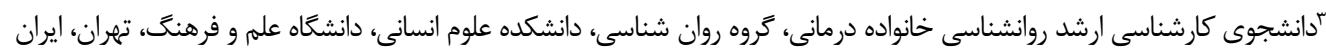

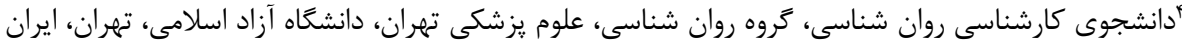

سابقه و هدف: طبق الكوهاى تنظيم هيجانى آسيبشناسى خوردن، رفتارهاى خورن بيماركون تلاشهايى ناسازكارانه براى اجتناب يا

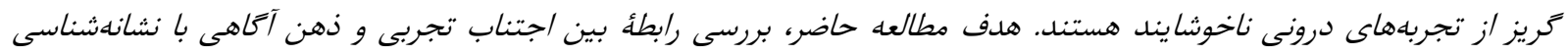

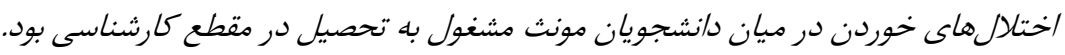

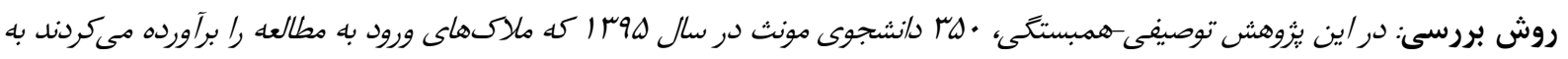

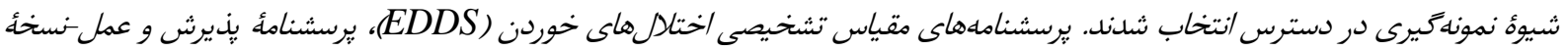

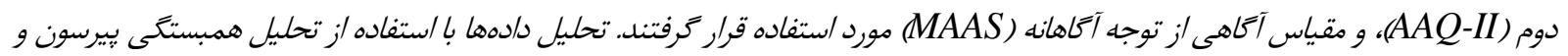
تحليل ركرسيون קندكانه انجام شد.

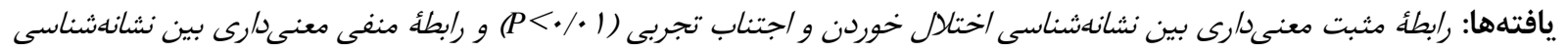

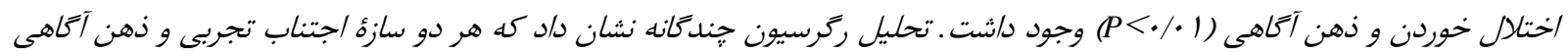

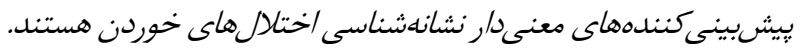

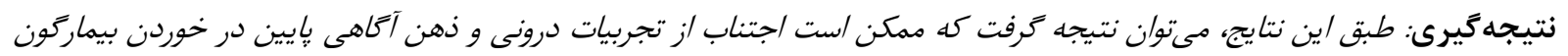

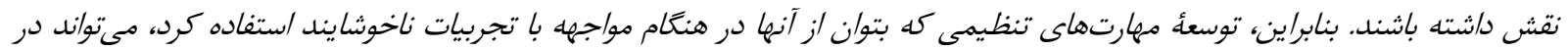

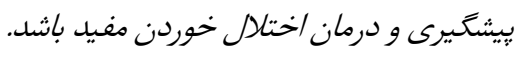

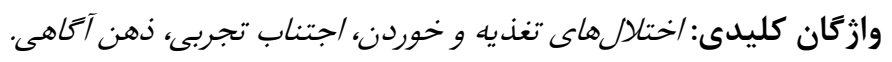

همبودى بالايى دارند، و با مركَومير و ميزان عود بالا مرتبط مقدمه

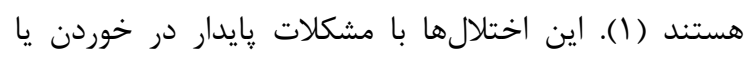

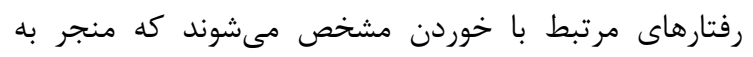

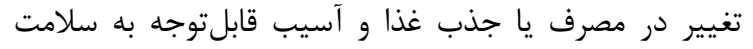

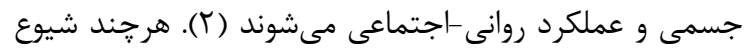

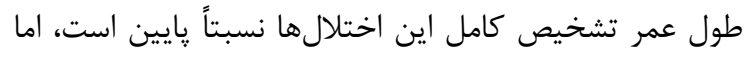
ميزان قابل توجهى از جوانان و بهخصوص دختران اختران جوان اختلالهاى تغذيه و خوردن جزو مقاومترين اختلالهاى روانى

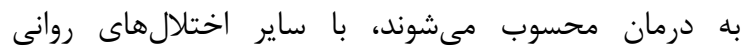

آدرس نويسنده مسئول: تهران، دانشكاه علم و فرهنك، دانشكده علوم انسانى، كروه روان شناسى، دكتر محسن كجويى (email: kachooei.m@gmail.com ORCID ID: 0000-0002-3070-4100

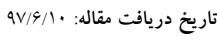
تاريخ بذيرش مقاله: تاريخ دربافت مقاله 
تجربى است و بلصورت حضور هدفمند و بدون قضاوت در زمان

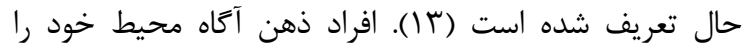

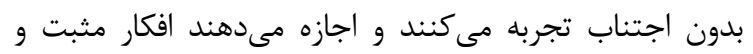

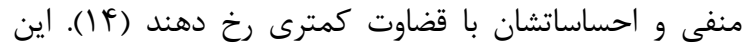

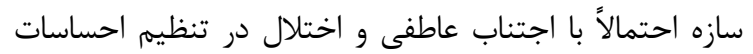

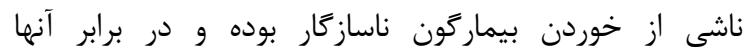
محافظت كننده است (ها). با اين حال، مطالعات اندكى رابطؤ

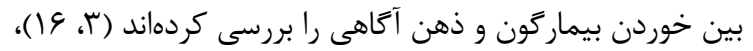

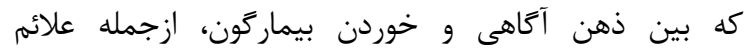

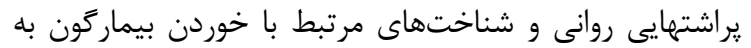
روابط معنى دارى دست يافتهاند.

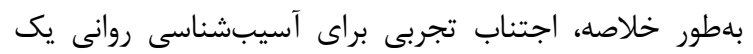

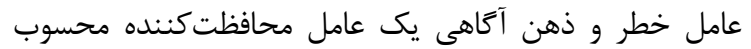
مىشود. روابط مفهومى بين ذهن آكاهى و اجتناب تجربى بسيار

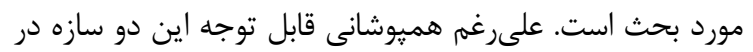

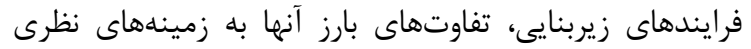

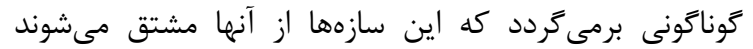

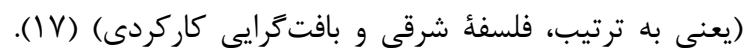
همجنين، درحالى كه ذهنآكاهى به عنوان يك صفت (trait)

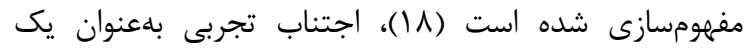

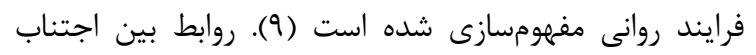
تجربى و ذهن آكاهى در مطالعات بِيشين در حوزههاى مختلف

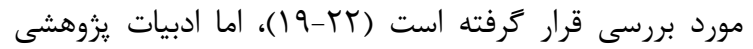

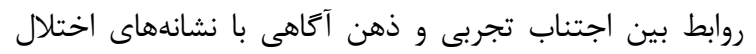

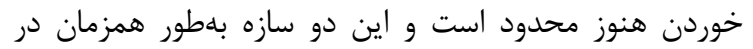

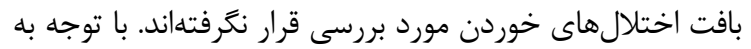
افزايش شيوع اختلالهاى خوردن در سالهاى اخدي اخير، يِامدهاى

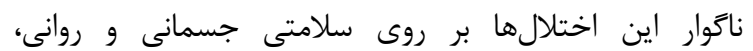

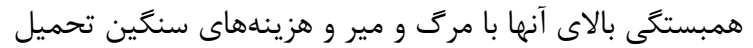

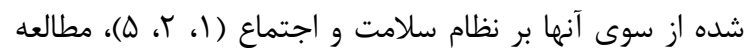

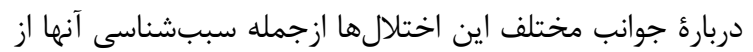
اهميت ويزماى برخوردار است. افزون بر اين، كاستىها و و ودينا

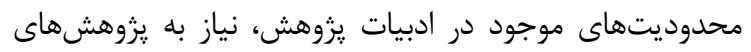

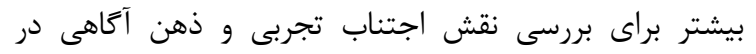

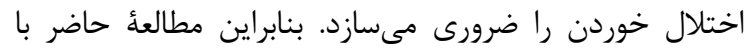

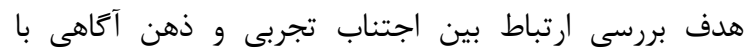

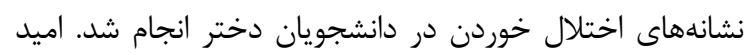
است كه يافتههاى حاصل از اين مطالعه بتوانند به شناخت بيشتر اختلالهاى خوردن و تدوين مداخلات درمانى اثربخش إنش براى اختلالهاى خوردن كمك كنند.
نشانههاى نكرشهاى اختلال خوردن (مثل نكرانى دربارة وزن

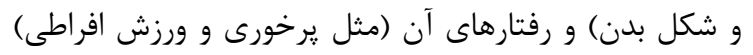
را ززارش مى كنند (سا). براى مثال، مطالعهاى در دان دانشجويان

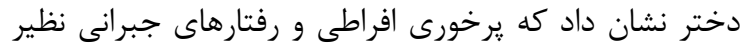

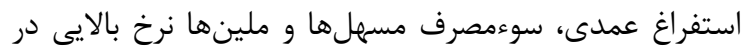

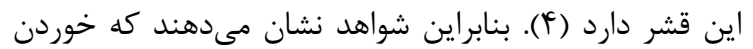

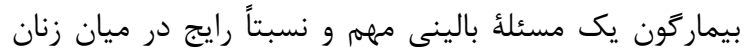
جوان است. در نتيجه، درك عميقتر آسيبشناسى اين اختلالها مىتواند نقش مهمى در اقدامات درمان و بِيشگيرى

داشته باشد (ه).

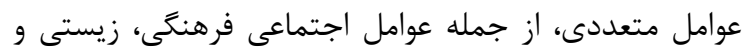

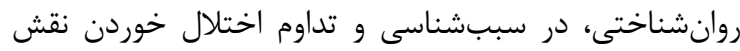
دارند (9). شواهد حاكى از آن است كه افراد مبتلا به اختلال

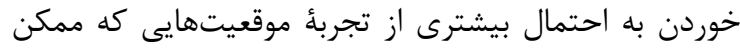

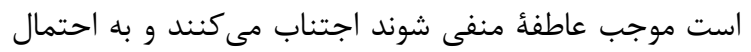

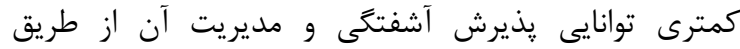

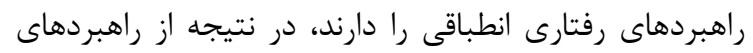

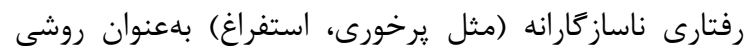

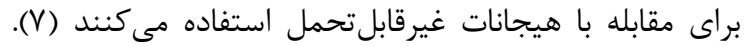

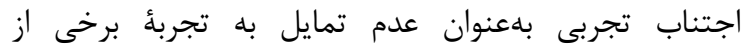
رويدادهاى درونى خاص (مانند احساسات، افكار يا احساسات

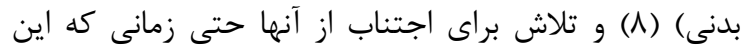
رفتار اجتنابى موجب آسيب مىشود تعريف شده است (9) (9).

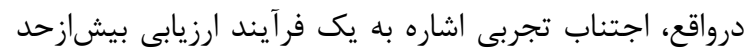

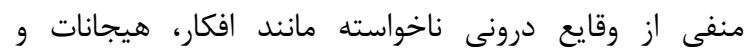

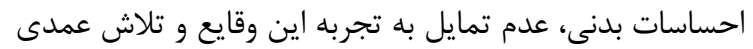

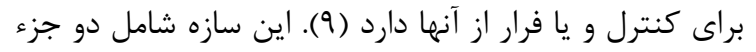

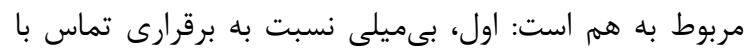
تجارب شخصى (احساسهاى بدنى، هيجانها، افكار، خاطرات

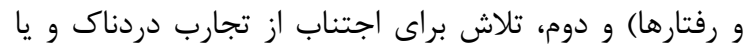

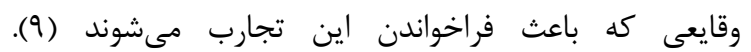
باطوركلى، مطالعات نشان دادهاند كه اجتناب تجربى نقشى إنى

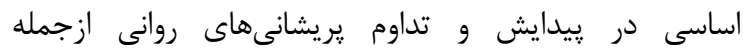

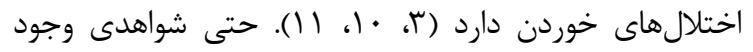

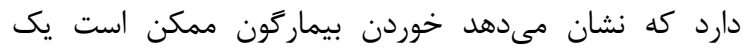
كاركرد اجتناب تجربى نيز داشته باشد (r) (1).

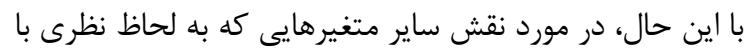
مدل اجتناب تجربى اختلالهاى خوردن همسو هستند

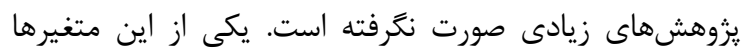

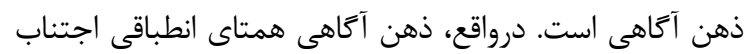


براساس مـلاكهـاى تشخيصى راهنمـاى تشخيصى و آمـارى

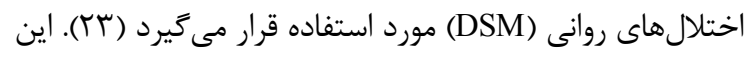

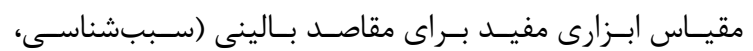

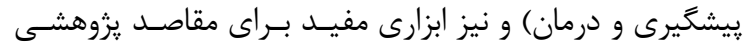

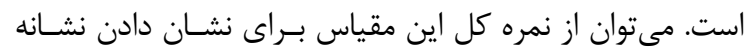

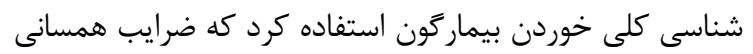

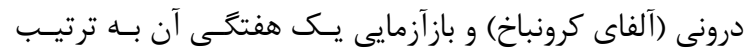

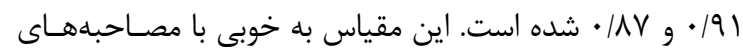

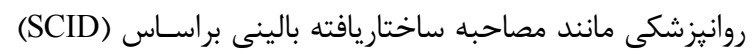

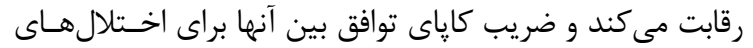

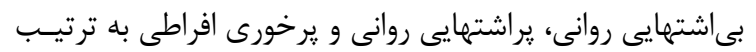

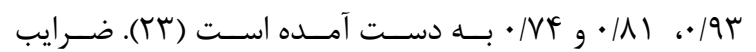

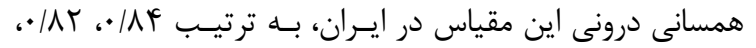

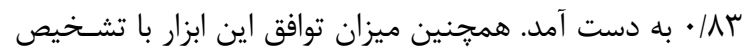

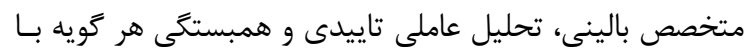

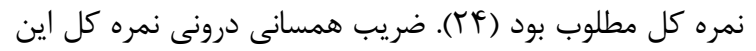

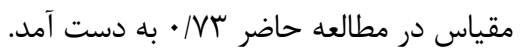

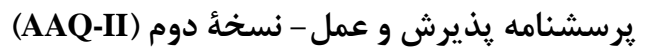

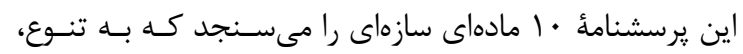

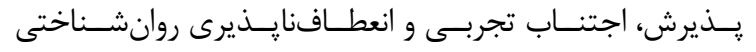

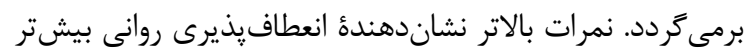

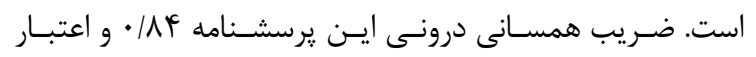

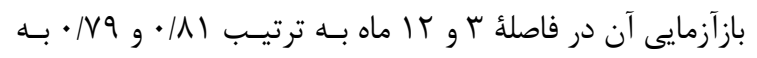

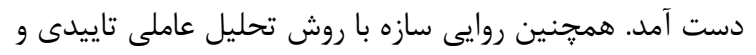

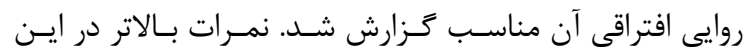

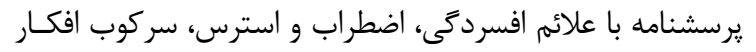

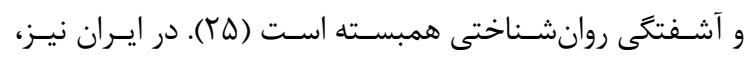

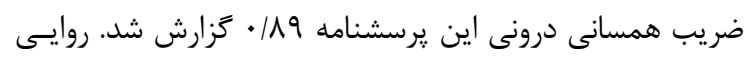
همكراى آن نيز با افسردگى، اضطزاب، سلامت روان و و مشكل در درد

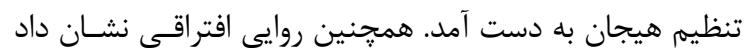

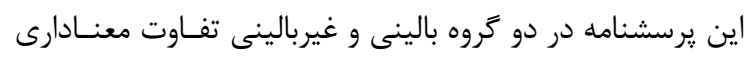

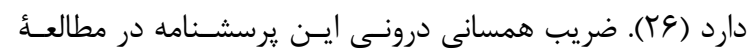

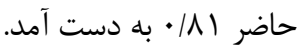

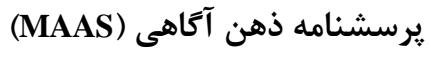

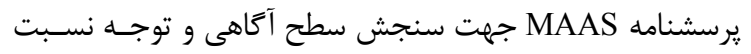

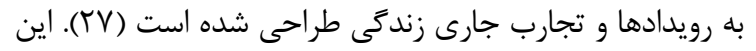

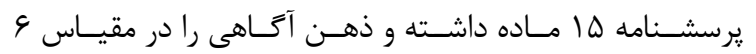

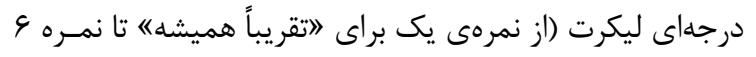

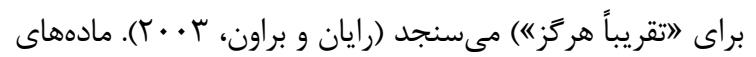

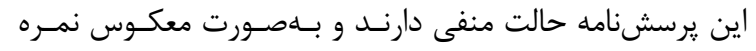

\section{مواد و روشها - - ماد}

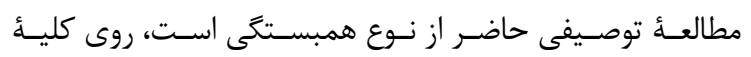

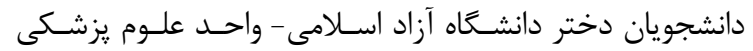

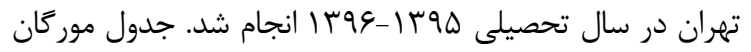

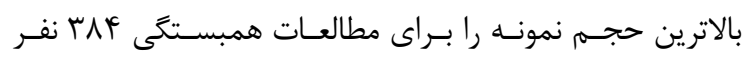

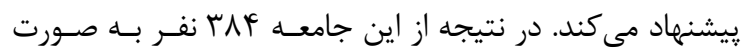

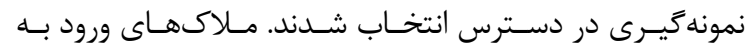

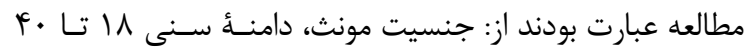

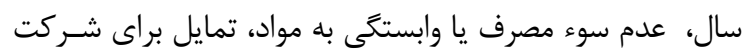

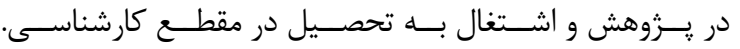

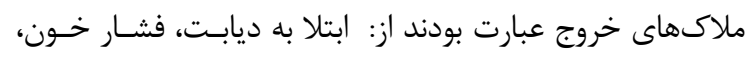

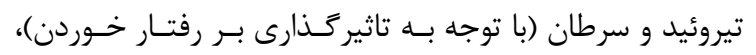

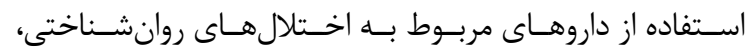

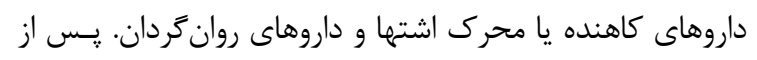
حذف يرسشنامههاى مخدوش و يرسشنامههايى كه در تضـاد بـا

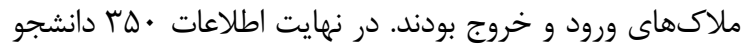

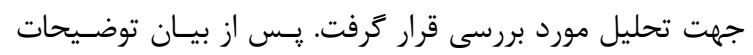

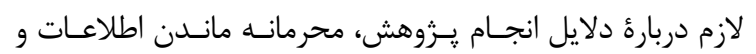

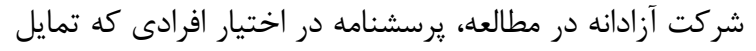

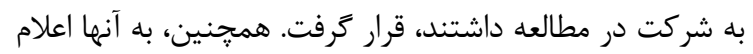

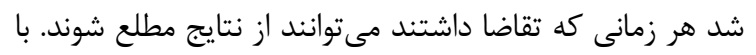

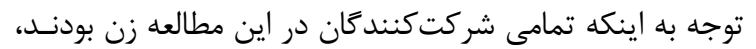

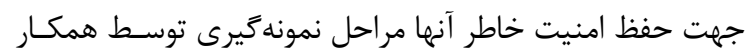

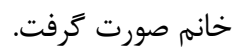

يرسشنامه اطلاعات جمعيتشناسى

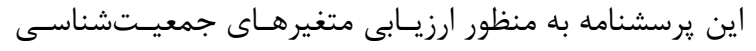

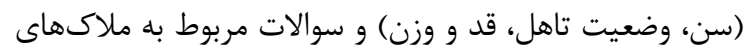

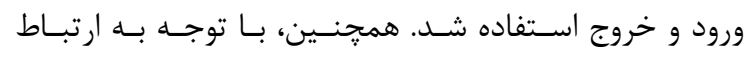
اختلالهاى خوردن با جاقى محاسبه نمايه تودؤ بـدنى (BMI)

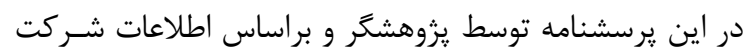

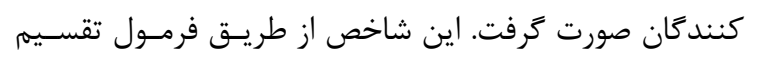

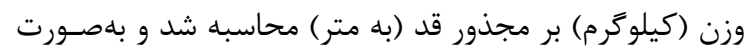

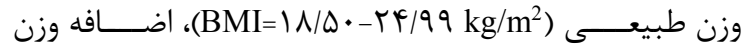

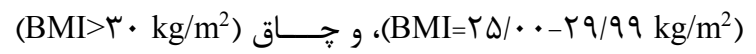

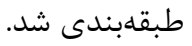

\section{مقياس تشخيصى اختلالهاى خوردن (EDDS)}

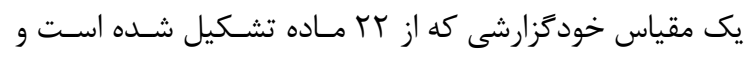

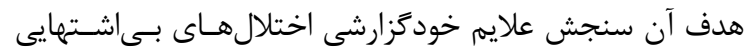
روانى (AN)، يراشتهايى روانى (BN) و يرخورى افراطى (BED) 
يافتهها

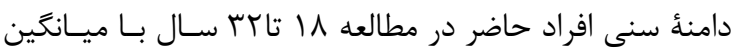

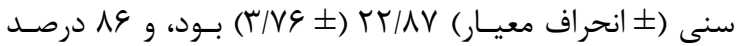

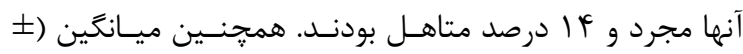

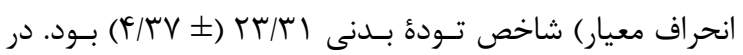

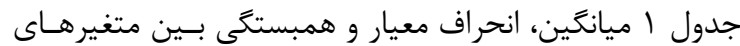

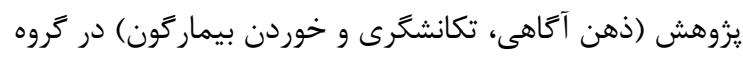
نمونه به نمايش در آمده است.

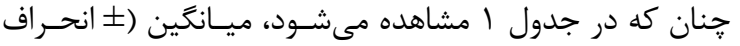

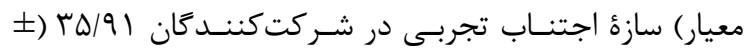

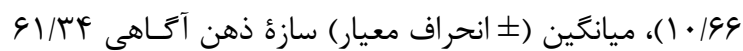
(l)/AV I)

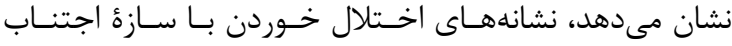

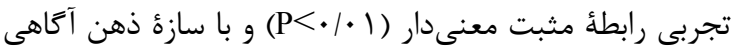

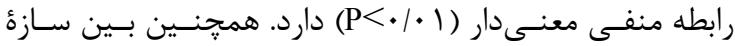

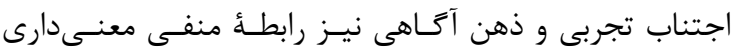

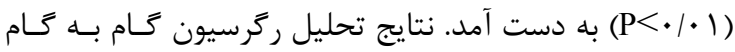
براى بيشبينى نشانهاى اختلال خوردن از طريق نمـرهــاى

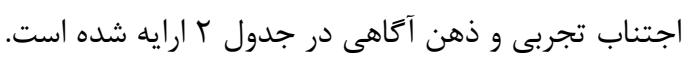

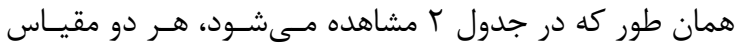
اجتناب تجربى و ذهن آكاهى قادر به بِيشبينى معنادار نشـانه

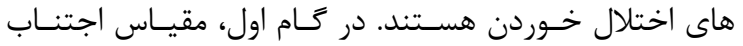

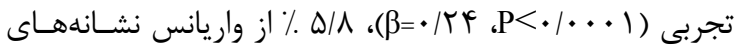

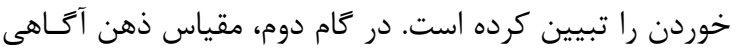

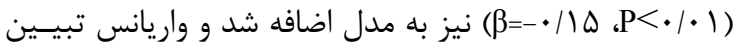

كذارى مىشوند. از جمع مادها يك نمرة كلى براى ذهن آكَاهى

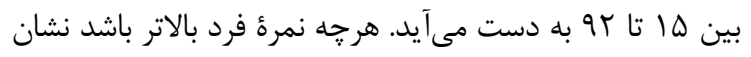

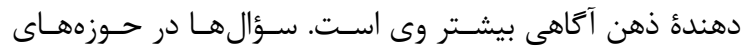
شناختى، هيجانى، بين فردى، جسمى و ديخر حوزههاى عمومى دئى

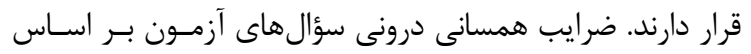

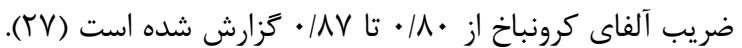

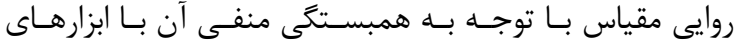

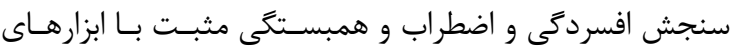
سنجش عاطفهى مثبت و حرمت خود، كافى كزارش شده است

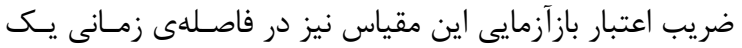

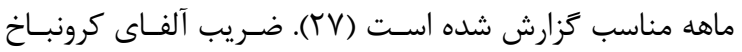

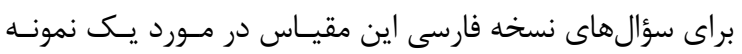

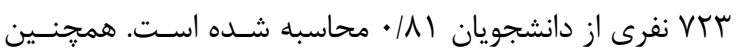

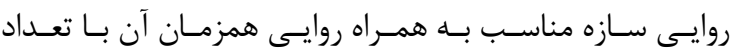

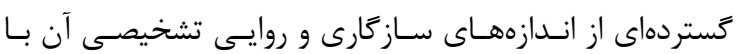

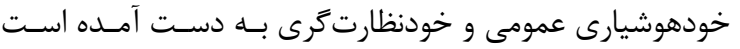

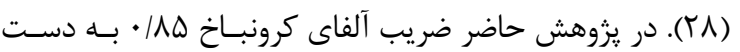

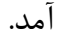

تحليل دادهاى جمع آورى شده با اسـتفاده از روش همبسـتكى يرسيرن و تجزيه و تحليل سهم هر يـك از سـازههـاى اجتنـاب

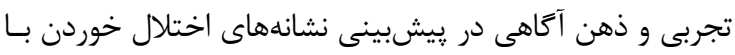

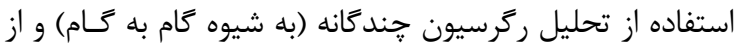
طريق نرمافزار بستؤآمارى براى علـوم اجتمـاعى (SPSS) انجـام

\begin{tabular}{|c|c|c|c|c|c|c|}
\hline \multirow[b]{2}{*}{ r } & & & & \multicolumn{3}{|c|}{ جدول ا. ميانكَين و انحراف معيار و ضرايب همبستگى متغيرهاى يزوهش } \\
\hline & $r$ & r & 1 & انحراف معيار & ميانكَين & متغير | متغر \\
\hline & & & - & $r / T r$ & Tr/TI & 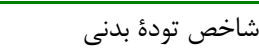 \\
\hline & & - & $\cdot / 49^{* t a n}$ & 1.191 & $19 / \cdot r$ & 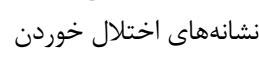 \\
\hline & - & $\cdot \pi r^{* * m}$ & $.1 \cdot 1$ & 1.199 & $r \Delta / 91$ & 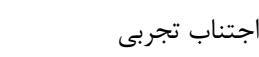 \\
\hline- & $-\cdot / 49^{m *}$ & $-\cdot / r^{* * * *}$ &.$- / . r$ & $11 / \wedge V$ & $91 / \pi 4$ & ذهن آكًاهى \\
\hline
\end{tabular}

$* \mathrm{P}<\cdot / \cdot \Delta * * \mathrm{P}<\cdot / \cdot 1$

جدول ז. نتايج تحليل ركرسيون كام به كام براى بيشبينى نشانههاى اختلال خوردن از طريق نمرههاى اجتناب تجربى و ذهن آكاهى

\begin{tabular}{|c|c|c|c|c|c|c|c|c|}
\hline $\mathrm{P}$ & $\mathrm{t}$ & $\beta$ & $\mathrm{SE}$ & B & تعديل شده R2 & $\mathrm{R}^{2}$ & متغيرهاى بيشبين & كام \\
\hline$\cdot 1 \cdot \cdots 1$ & F/gF & $\cdot|r| F \mid$ & $\cdot 1 \cdot \Delta F$ & - ITFq & $\cdot / \cdot \Delta \varphi$ & $\cdot / \cdot \Delta \Lambda$ & اجتناب تجربى & 1 \\
\hline$\cdot / \cdot r$ & T/৭9 &.$/ 1 \mathrm{VT}$ & .1 .9 &.$/ 1 \mathrm{VV}$ & & & اجتناب تجربى & r \\
\hline$\cdot 1 \cdot 1$ & $-r / 09$ & $-\cdot / 10$ & $\cdot 1 \cdot \Delta F$ &.$- / 1149$ & $\cdot \mid \cdot \vee 1$ & $\cdot 1 \cdot \sqrt{ } 4$ & ذهن آكاهى & \\
\hline
\end{tabular}




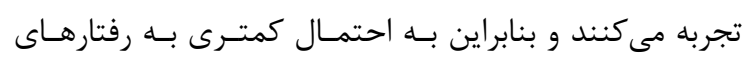

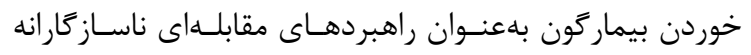
متوسل مىشوند.

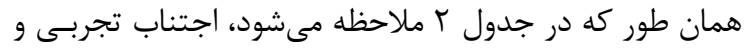

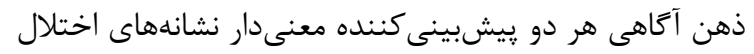

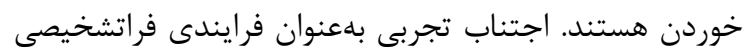

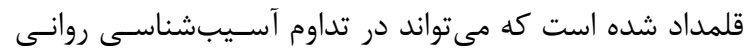

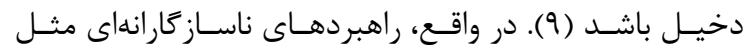

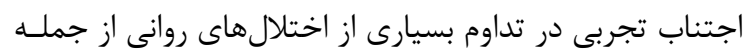

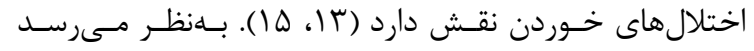

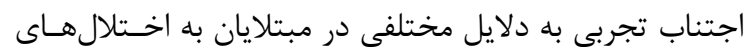

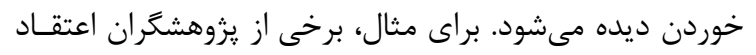

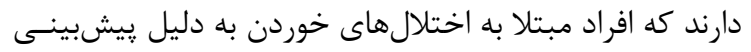

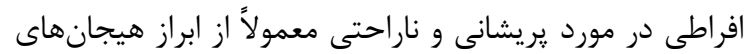

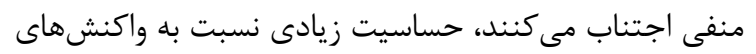
ديكر ان دارند، و محيطهايى كه به لحاظ هيجانى آرام و وِايـدار

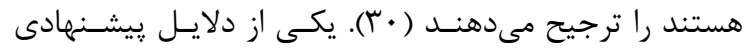

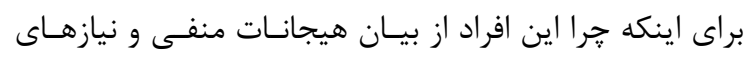

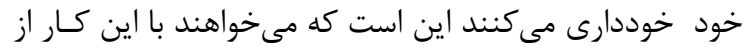

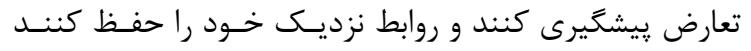

حضور سازه ذهن آكاهى در مدل ركرسيون نشانهاى اخـتلال

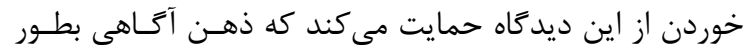

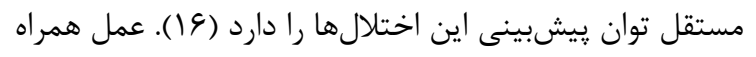

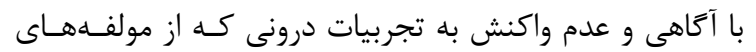

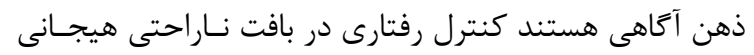

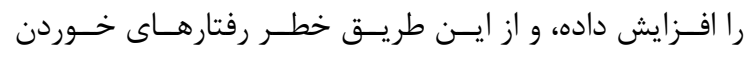

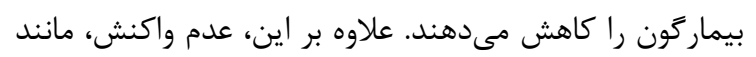

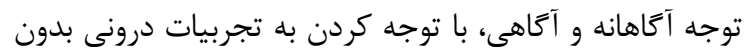

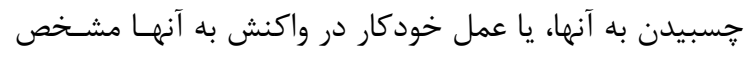
مىشود، كه ممكن است احتمال ارتكاب رفتارهاى ناسـازعارانه

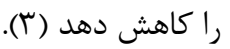

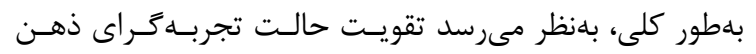

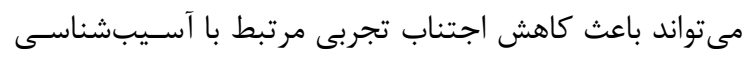

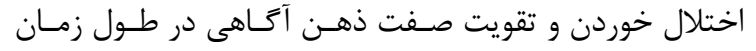

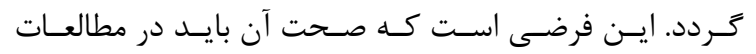

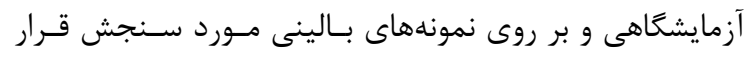

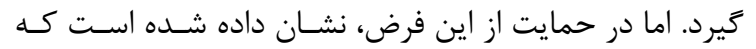

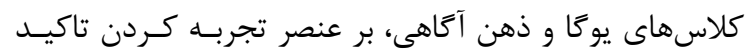

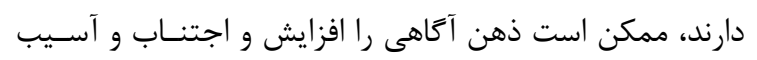

شده نشانههاى اختلال خوردن را بـه V/9 ٪ رسـاند و در واقـع

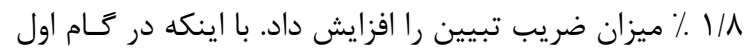

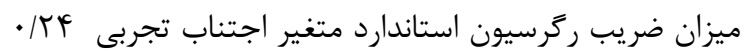

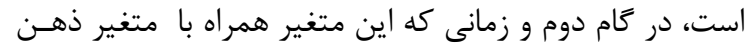

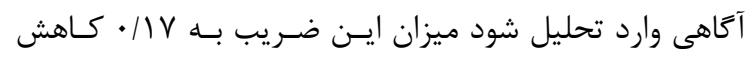

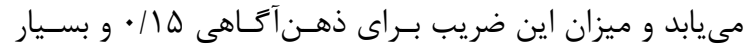

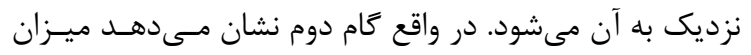

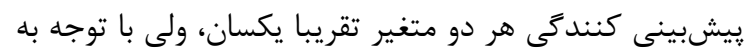

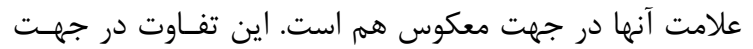
با توجه به مفهوم متغيرها منطقى به نظر مىرسد.

\section{بحث}

يزوهش حاضر با هدف بررسى رابطـهـ بـين اجتنـاب تجربسى و

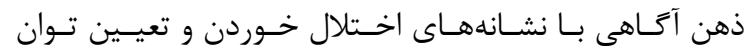

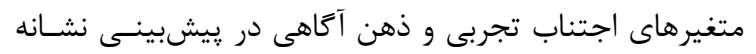

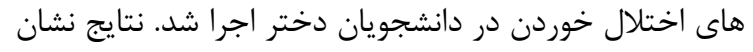

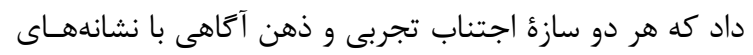

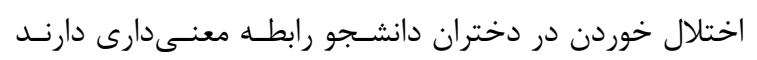

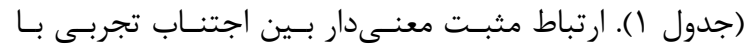

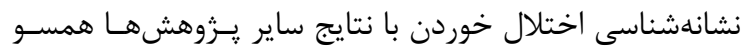

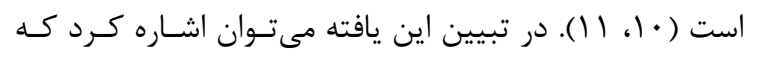

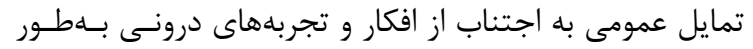

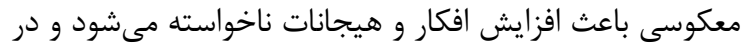

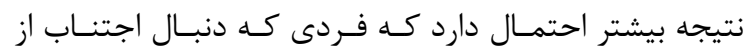

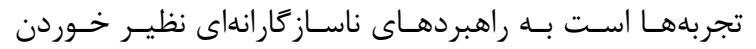

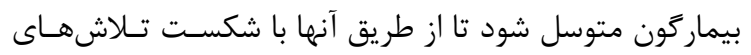

اجتنابى خود مقابله كند (9) (9.)

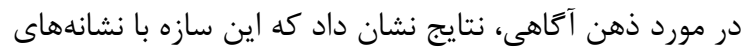

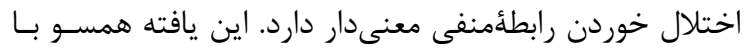

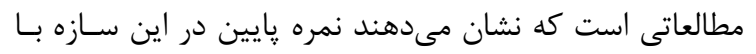
نشانهشناسى اختلالهاى خوردن مرتبط است (ع) (بآ). مطالعه

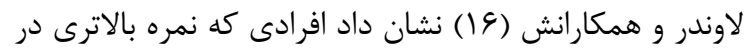

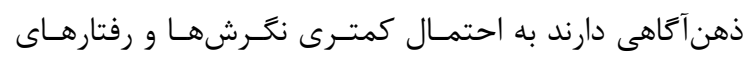

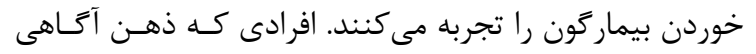
خصيصهاى بالاترى دارند نسبت به تجربيات شناختى و عاطفى

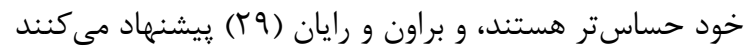

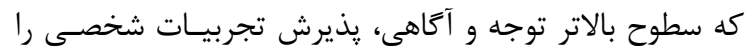

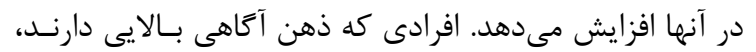

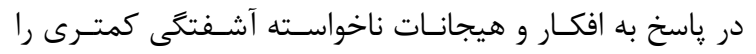




$$
\begin{aligned}
& \text { كروههاى ديخر را منتفى نمىسازد. در نتيجه، يُيشنهاد مىشود } \\
& \text { يزوهشهايى در نمونههاى ديخر (از جمله نمونههـاى بـالينى و }
\end{aligned}
$$

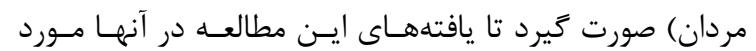

$$
\begin{aligned}
& \text { بررسى قرار گيرد. }
\end{aligned}
$$

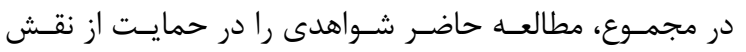

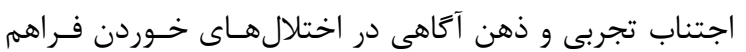

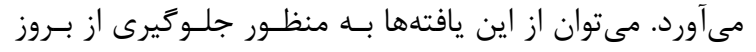

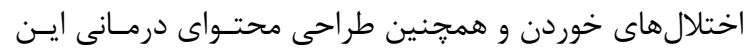

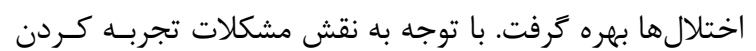

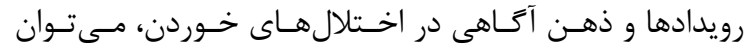

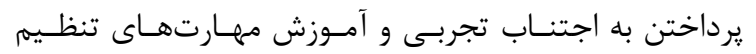

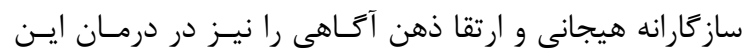

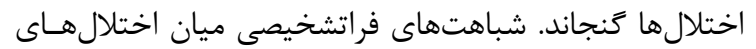

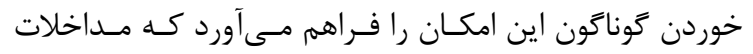

$$
\begin{aligned}
& \text { مبتنى بر تنظيم هيجان و ارتقا ذهن آكاهى براى تمامى طيف إنى } \\
& \text { اختلال خوردن قابل كاربرد باشد. } \\
& \text { تشكر و قدردانى } \\
& \text { برخود لازم مى دانيم از شركت كنـندان و ساير عزيزانى كـه در }
\end{aligned}
$$

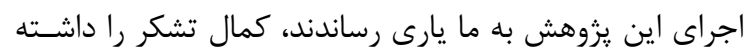

$$
\begin{aligned}
& \text { باشيم. }
\end{aligned}
$$

\section{REFERENCES}

1. Elmquist J, Shorey RC, Anderson SE, Stuart GL. A preliminary investigation of the relationship between dispositional mindfulness and eating disorder symptoms among men in residential substance use treatment. Addict Res Theory 2017;25:67-73.

2. American Psychiatric Association. Diagnostic and statistical manual of mental disorders (DSM-5®). Washington, DC: American Psychiatric Pub; 2013.

3. Lavender JM, Gratz KL, Tull MT. Exploring the relationship between facets of mindfulness and eating pathology in women. CBT 2011;40:174-82.

4. Luce KH, Crowther JH, Pole M. Eating disorder examination questionnaire (EDE-Q): Norms for undergraduate women. Int J Eat Disord 2008;41:273-6.

5. Skinner KD, Rojas SM, Veilleux JC. Connecting Eating Pathology with Risk for Engaging in Suicidal Behavior: The Mediating Role of Experiential Avoidance. Suicide Life Threat Behav 2017;47:3-13.

6. Stice E. A prospective test of the dual-pathway model of bulimic pathology: mediating effects of dieting and negative affect. J Abnor Psychol 2001;110:124-35.

7. Hambrook D, Oldershaw A, Rimes K, Schmidt U, Tchanturia K, Treasure J, et al. Emotional expression, self-silencing, and distress tolerance in anorexia nervosa and chronic fatigue syndrome. Br J Clin Psychol 2011;50:31025 .

8. Hayes SC, Strosahl KD, Wilson KG. Acceptance and commitment therapy: An experiential approach to behavior change. New York: Guilford Press; 1999.

9. Hayes SC, Wilson KG, Gifford EV, Follette VM, Strosahl K. Experiential avoidance and behavioral disorders: A functional dimensional approach to diagnosis and treatment. J Consult Clin Psychol 1996;64:1152-68.

10. Lavender JM, Anderson DA. Contribution of emotion regulation difficulties to disordered eating and body dissatisfaction in college men. Int J Eat Disord 2010;43:352-7. 
11. Rawal A, Park RJ, Williams JMG. Rumination, experiential avoidance, and dysfunctional thinking in eating disorders. Behav Res Ther 2010;48:851-9.

12. Polivy J, Herman CP. Etiology of binge-eating: Psychological mechanisms. InC.G. Fairburn, \& G. T. Wilson (Eds.), Binge-eating: Nature, assessment, and treatment(pp. 144-172). New York: Guilford Press; 1993.

13. Bishop SR, Lau M, Shapiro S, Carlson L, Anderson ND, Carmody J, et al. Mindfulness: A proposed operational definition. Clin Psychol Sci Pr 2004;11:230-41.

14. Brown KW, Ryan RM, Creswell JD. Mindfulness: Theoretical foundations and evidence for its salutary effects. Psychol Inq 2007;18:211-37.

15. Hayes AM, Feldman G. Clarifying the construct of mindfulness in the context of emotion regulation and the process of change in therapy. Clin Psychol Sci Pr 2004;11:255-62.

16. Lavender JM, Jardin BF, \& Anderson DA. Bulimic symptoms in undergraduate men and women: Contributions of mindfulness and thought suppression. Eat Behave 2009;10:228-31.

17. Block-Lerner J, Salters-Pedneault K, Tull MT. Acceptance and mindfulness-based approaches to anxiety. New York: Springer; 2005. P.71-99.

18. Kabat-Zinn J. Full catastrophe living: Using the wisdom of your body and mind to face stress, pain, and illness. New York: Delacorte Press; 1990.

19. Moore SD, Brody LR, Dierberger AE. Mindfulness and experiential avoidance as predictors and outcomes of the narrative emotional disclosure task. J clin Psychol 2009;65:971-88.

20. Thompson BL, Waltz J. Mindfulness and experiential avoidance as predictors of posttraumatic stress disorder avoidance symptom severity. J Anxiety Disord 2010;24:409-15.

21. Riley B. Experiential avoidance mediates the association between thought suppression and mindfulness with problem gambling. J Gambl Stud 2014;30:163-71.

22. Mahoney CT, Segal DL, Coolidge FL. Anxiety sensitivity, experiential avoidance, and mindfulness among younger and older adults: Age differences in risk factors for anxiety symptoms. The Int J Aging Hum Dev 2015;81:217-40.

23. Stice E, Telch CF, Rizvi SL. Development and validation of the Eating Disorder Diagnostic Scale: a brief selfreport measure of anorexia, bulimia, and binge-eating disorder. Psycholo Assess 2000;12:123-31.

24. Khabir L, Mohamadi N, Rahimi C. The Validation of Eating Disorder Diagnostic Scale (EDDS). J Kermanshah Univ Med Sci 2014;18:100-7. [In Persian]

25. Bond FW, Hayes SC, Baer RA, Carpenter KM, Guenole N, Orcutt HK, et al. Preliminary psychometric properties of the Acceptance and Action Questionnaire-II: A revised measure of psychological inflexibility and experiential avoidance. Behav Ther 2011;42:676-88.

26. Abasi E, Fati L, Molodi R, Zarabi H. Psychometric properties of Persian version of acceptance and action questionnaire-ii. Journal of Psychological Models and Methods 2013;10:65-80. [In Persian]

27. Brown KW, Ryan RM. The benefits of being present: mindfulness and its role in psychological well-being. J Pers Soc Psychol 2003;84:822-48.

28. Ghorbani N, Watson PJ, Weathington BL. Mindfulness in Iran and the United States: Cross-cultural structural complexity and parallel relationships with psychological adjustment. Curr Psychol 2009;28:211-24.

29. Brown KW, Ryan RM. Perils and promise in defining and measuringmindfulness: Observations from experience. Clin Psychol Sci Pr 2004;11:242-8.

30. Geller J, Cockell SJ, Hewitt PL, Goldner EM, Flett GL. Inhibited expression of negative emotions and interpersonal orientation in anorexia nervosa. Int J Eat Disord 2000;28:8-19.

31. Schmidt U, Treasure J. Anorexia nervosa: Valued and visible. A cognitive-interpersonal maintenance model and its implications for research and practice. Br J Clin Psychol 2006;45:343-66.

32. Rawal A, Enayati J, Williams JMG, Park RJ. A mindful approach to eating disorders. HCPJ 2009;9:16-20.

33. Wildes JE, Ringham RM, Marcus MD. Emotion avoidance in patientswith anorexia nervosa: Initial test of a functional model. Int J Eat Disord 2010;43:398-404.

34. Vohs KD, Heatherton TF, Herrin M. Disordered eating and the transitionto college: A prospective study. Int J Eat Disord 2001;29:280-8. 